\title{
Leaf level emission measurement of sesquiterpenes and oxygenated sesquiterpenes from desert shrubs and temperate forest trees using a liquid extraction technique
}

\author{
Sou N. Matsunaga, ${ }^{1 *}$ Alex B. Guenther, ${ }^{1}$ Jim P. Greenberg,,${ }^{1}$ Mark Potosnak, ${ }^{2}$ Maria Papiez,${ }^{2}$ \\ Tsutom Hiura, ${ }^{3}$ Shungo Kato, ${ }^{4}$ Satoshi Nishida, ${ }^{4}$ Peter Harley ${ }^{1}$ and Yoshizumi KaJiI ${ }^{4}$ \\ ${ }^{1}$ Atmospheric Chemistry Division, National Center for Atmospheric Research, 3450 Mitchell Lane, Boulder, CO 80301, U.S.A. \\ ${ }^{2}$ Desert Research Institute, 2215 Raggio Parkway, Reno, NV 89512, U.S.A. \\ ${ }^{3}$ Tomakomai Experimental Forest, Forest Research Station, Field Science Center for Northern Biosphere, Hokkaido University, \\ Takaoka, Tomakomai, Hokkaido 053-0035, Japan \\ ${ }^{4}$ Faculty of Urban Environmental Sciences, Tokyo Metropolitan University, \\ 1-1 Minami-Osawa, Hachioji, Tokyo 192-0397, Japan
}

(Received January 21, 2008; Accepted December 8, 2008)

\begin{abstract}
Biogenic emission of sesquiterpene (SQT) and oxygenated SQT (OSQT) were measured from the dominant vegetation in a desert shrubland and urban area (Las Vegas, Nevada, U.S.A.), and at temperate forest sites at Niwot Ridge, Colorado, U.S.A., Tomakomai, Hokkaido, Japan and Tumbarumba, New South Wales, Australia. Additional measurements were conducted using greenhouse grown plants. The sampling technique, based on solid adsorbent preconcentration and liquid extraction, is suitable for measuring high molecular weight and low volatility compounds such as OSQTs. Fourteen SQT and OSQT (10 SQT and 4 OSQT) were identified in the field experiments. Total emission rates of SQTs and OSQTs varied from the detection limit to $7.6 \mu \mathrm{gC} \mathrm{g}^{-1} \mathrm{~h}^{-1}$ (average: 0.74 ) and $3.7 \mu \mathrm{gC} \mathrm{g}^{-1} \mathrm{~h}^{-1}$ (average: 0.31 ), respectively, and varied with plant species and location. Environmental conditions, including temperature and precipitation, appeared to influence emission rates. Canopy level emission of SQT and OSQT in Tomakomai were also estimated using an emission model. The emission rate of SQT and OSQT ranged from 72 to $710 \mu \mathrm{gC} \mathrm{m}^{-2} \mathrm{~h}^{-1}$ (average, 460 in daytime) and from 38 to 370 $\mu \mathrm{gC} \mathrm{m}{ }^{-2} \mathrm{~h}^{-1}$ (average, 240 in daytime), respectively. Their contributions can be very high in specific regions and seasons. Given the relatively high reactivity and secondary organic aerosol yields of SQTs and OSQTs, it is likely that these compounds influence atmospheric constituents in at least some areas.
\end{abstract}

Keywords: sesquiterpene, biogenic VOC, aerosol formation, biosphere atmosphere interaction, biogenic emission

\section{INTRODUCTION}

Terrestrial vegetation emits numerous volatile organic compounds (VOCs). These biogenic VOCs (BVOCs) have an important role in tropospheric chemistry due to their high reactivity with atmospheric oxidants such as ozone, $\mathrm{OH}$ and $\mathrm{NO}_{3}$. Therefore, numerous studies have been conducted in recent decades to determine their sources and sinks. The results of these studies have been used to develop emission models that predict emission rates under various conditions for some BVOCs. For example, isoprene is the most important and thoroughly studied BVOC and has the highest global emission rate, estimated to be $440-660 \mathrm{TgC}^{-1}$ (Guenther et al., 2006). However, emission rates, geographic distribution and environ-

*Corresponding author (e-mail: s-matsunaga@pecj.or.jp)

*Present address: JPEC-ATRI, 4-10, Onodai 1-chome, Midori-ku, Chiba-shi, Chiba 267-0056, Japan.

Copyright @ 2009 by The Geochemical Society of Japan. mental controls over many other BVOCs remain highly uncertain. For example, there are fewer studies on high molecular weight BVOCs such as sesquiterpene (SQT) due to analytical difficulties. Therefore, no emission model can accurately predict SQT emission. Because SQTs are produced by plants to protect themselves from herbivore (Smith, 1963; Turlings et al., 1990; Werner, 1995), fungi (Himejima et al., 1992; Sonboli et al., 2006), oxidants (Sonboli et al., 2005), mutagenesis (GomesCarneiro et al., 2005) and/or physical damage (Villegas et al., 2001), it is much more difficult to predict their emission due to the difficulties in characterizing their response to these stresses. However, many of these high molecular weight BVOC are highly reactive, and many generate low volatility oxidation products that readily partition to the aerosol phase (Hoffmann et al., 1997; Calogirou et al., 1997). These features suggest that SQTs and other high molecular weight reactive BVOCs can have a significant role in atmospheric chemistry, and it is critical to improve estimates of their emissions. 
Direct analysis of oleoresins and essential oils has demonstrated that plants contain a wide array of monoterpenes and SQTs. Many of these compounds have also been detected as gaseous emissions from plants. Due to the high reactivity of most SQT with ozone, most enclosure measurement studies of emissions have used an oxidant free inlet airstream, and air exiting the enclosure has been collected onto a solid adsorbent. The compounds collected on the adsorbent are subsequently desorbed for analysis.

There are two different ways to release the compounds from the adsorbent: thermo-desorption and liquid extraction. Thermo-desorption, which has been used in most BVOC emission rate characterization studies, enables online analysis and all of the collected compounds can be injected into a gas chromatograph or other analytical instrument, thus providing automated operation and higher sensitivity (Helmig et al., 2003, 2004). However, thermodesorption has a limitation on molecular weight and polarity of the compounds to be desorbed. Low vapor pressure compounds, due to their high molecular weight and/ or high polarity, may not be removed completely from the adsorbent even when heated to temperatures around $350^{\circ} \mathrm{C}$. In addition, very high desorption temperatures may induce isomerization of terpenoid compounds. Liquid extraction with an organic solvent can remove compounds with a wide range of molecular weight and polarity from the adsorbent at room temperature, potentially resulting in less rearrangement. In this study, the liquid extraction technique was used to elute compounds collected on the adsorbent, in order to better identify and quantify high molecular weight BVOC and those with polar functional groups (e.g., alcohols). The liquid extraction and thermal desorption techniques were compared with measurements at the desert field site (a personal communication).

The current lack of observations describing SQT and oxygenated SQT emissions makes it difficult to determine the potential importance of these emissions from various ecosystems. The purpose of the study described in this manuscript was to characterize the magnitude and variability of SQT and oxygenated SQT emissions from important ecosystems and assess their potential importance for regional oxidant and aerosol distributions. The following sections describe the field observations and their integration into a global biogenic emission model that is used to characterize their relative contribution to regional emissions.

\section{FiELD STUdY DESCRIPTIONS}

Las Vegas, Nevada, U.S.A.

Plant enclosure samples were collected between July 1 and July 6, 2006 from typical urban and wild land desert 


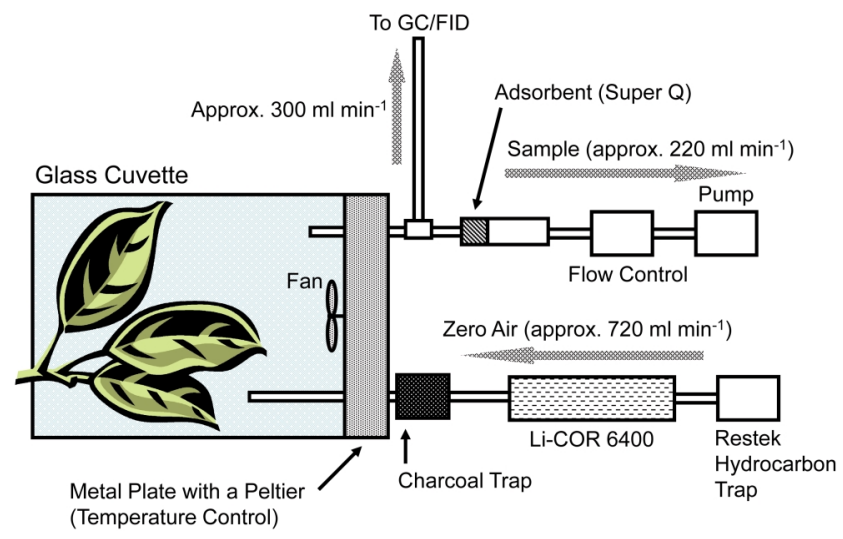

Fig. 1. Schematic diagram for a glass cuvette with temperature control used for sample collection in Las Vegas.

shrubs and trees located in a desert shrubland, a golf course, on the campus of the Desert Research Institute and at a city public park. Table 1 summarizes the plant species investigated at each of the four locations. Branches were enclosed in a 5-liter Teflon ${ }^{\circledR}$ enclosure bag without temperature control or a 1-liter glass cuvette with a temperature control (see Fig. 1). The sample air was separated and pulled into an in-situ GC/FID system for the analysis of isoprene and monoterpenes. Air, purified with a charcoal/molecular sieve trap, flowed continuously through the Teflon enclosure at a rate of approximately $1000 \mathrm{ml} \mathrm{min}^{-1}$ and through the glass enclosure at a rate of $720 \mathrm{ml} \mathrm{min}^{-1}$. $\mathrm{CO}_{2}$ concentration may be changed while going through the charcoal trap, however, the resulting $\mathrm{CO}_{2}$ concentration was close to ambient levels. $\mathrm{CO}_{2}$ and water vapor concentration in the zero air going into the glass cuvette were analyzed with a Li-COR 6400 (Li-COR Biosciences, Lincoln, NE, U.S.A.). The Li-COR 6400 has a second trap (Restek Hydrocarbon Trap, Restek, Bellefonte, PA, U.S.A.) on its air inlet. Air for VOC analysis was withdrawn from the enclosure at a rate of $220 \mathrm{ml}$ $\min ^{-1}$, and sampling times ranged from 1.5 to 4 hours. 16 samples (10 plant species) were collected during this experiment.

\section{Tomakomai, Hokkaido, Japan}

Measurements were conducted from August 22 to September 2, 2006 in the Hokkaido University's Tomakomai experimental forest which is located on the southern coast of Hokkaido Island $\left(42^{\circ} 40^{\prime} 41.92^{\prime \prime} \mathrm{N}, 141^{\circ} 35^{\prime} 40.96^{\prime \prime} \mathrm{E}\right)$ and is described in detail by Hiura $(2001,2005)$ and Shibata et al. (2005). Fifty-one samples were collected from six dominant plant species in the experimental forest. Between August 23 and September 2, samples were continuously collected from three bags without temperature control enclosing branches of Carpinus cordata
Blume, Acer mono Maximowicz and Quercus mongolica var. crispula, under typical ambient conditions of light and temperature. Three additional samples were collected from another 3 species (Dryopteris crassirhizoma, $S$. virga-aurea var. leiocarpa and Ulmus davidiana var. japonica) on September 1 and 2. Air entering the enclosure was purified with a charcoal trap and supplied into the enclosure bags with a flow rate of approximately 2000 $\mathrm{ml} \mathrm{min}^{-1}$. Air exiting the chamber was collected onto

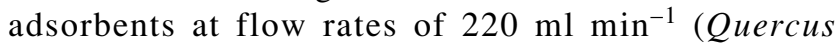

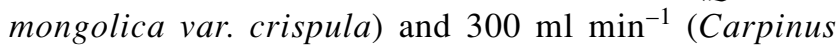
cordata Blume and Acer mono Maximowicz), and sampling times ranged from 2.5 to 8 hours.

\section{Tumbarumba, New South Wales, Australia}

Six samples were collected in a montane broadleaf forest near Tumbarumba flux station located in the Bago State forest in south eastern New South Wales, Australia $\left(35^{\circ} 30^{\prime} 20.5^{\prime \prime} \mathrm{S}, 148^{\circ} 09^{\prime} 07.5^{\prime \prime} \mathrm{E}\right.$, altitude $\left.1200 \mathrm{~m}\right)$ from November 12-14, 2006. The forest is dominated by $E u$ calyptus delegatensis and E. dalrympleana. The measurements were conducted as a component of the EUCAP study that characterized contributions of BVOC to secondary aerosol production and growth and is described by Suni et al. (2007). Midday temperatures ranged from above $20^{\circ} \mathrm{C}$ on November 12 and 14 to below $1{ }^{\circ} \mathrm{C}$ on November 13 after a spring snowstorm during the previous night. Samples were collected from 3 individuals each of the two dominant Eucalyptus species using the enclosure system described in Subsection "Tomakomai, Hokkaido, Japan". Air flowed through the enclosure at a rate of $1000 \mathrm{ml} \mathrm{min}{ }^{-1}$, and samples for analysis were drawn from air exiting the bag at a flow rate of $200 \mathrm{ml}$ $\mathrm{min}^{-1}$ for 1.2 to 2 hours.

Niwot Ridge and NCAR greenhouse, Colorado, U.S.A.

SQT and OSQT emissions from Cedar were collected at the University of Colorado Mountain Research Station near Niwot Ridge, CO, U.S.A. $\left(40^{\circ} 01^{\prime} 57.57^{\prime \prime} \mathrm{N}\right.$, $105^{\circ} 31^{\prime} 56.06^{\prime \prime} \mathrm{W}$, altitude $2900 \mathrm{~m}$ ) on June 29 using the same enclosure bag without temperature control used for the Las Vegas experiment (see Subsection "Las Vegas, Nevada, U.S.A."). Additional measurements were made on Black oak (Quercus velutina) and Silver maple (Acer saccharmum) growing in pots in a greenhouse at NCAR, Boulder, CO, U.S.A.

\section{METHODS}

\section{Sample treatment}

Air exiting the various enclosure systems was collected onto $30 \mathrm{mg}$ of Super Q adsorbent (Alltech, Columbia, MD, U.S.A.) in a $6.3 \mathrm{~mm}$ diameter glass tube (Volatile Collection Trap, Analytical Research Systems, 


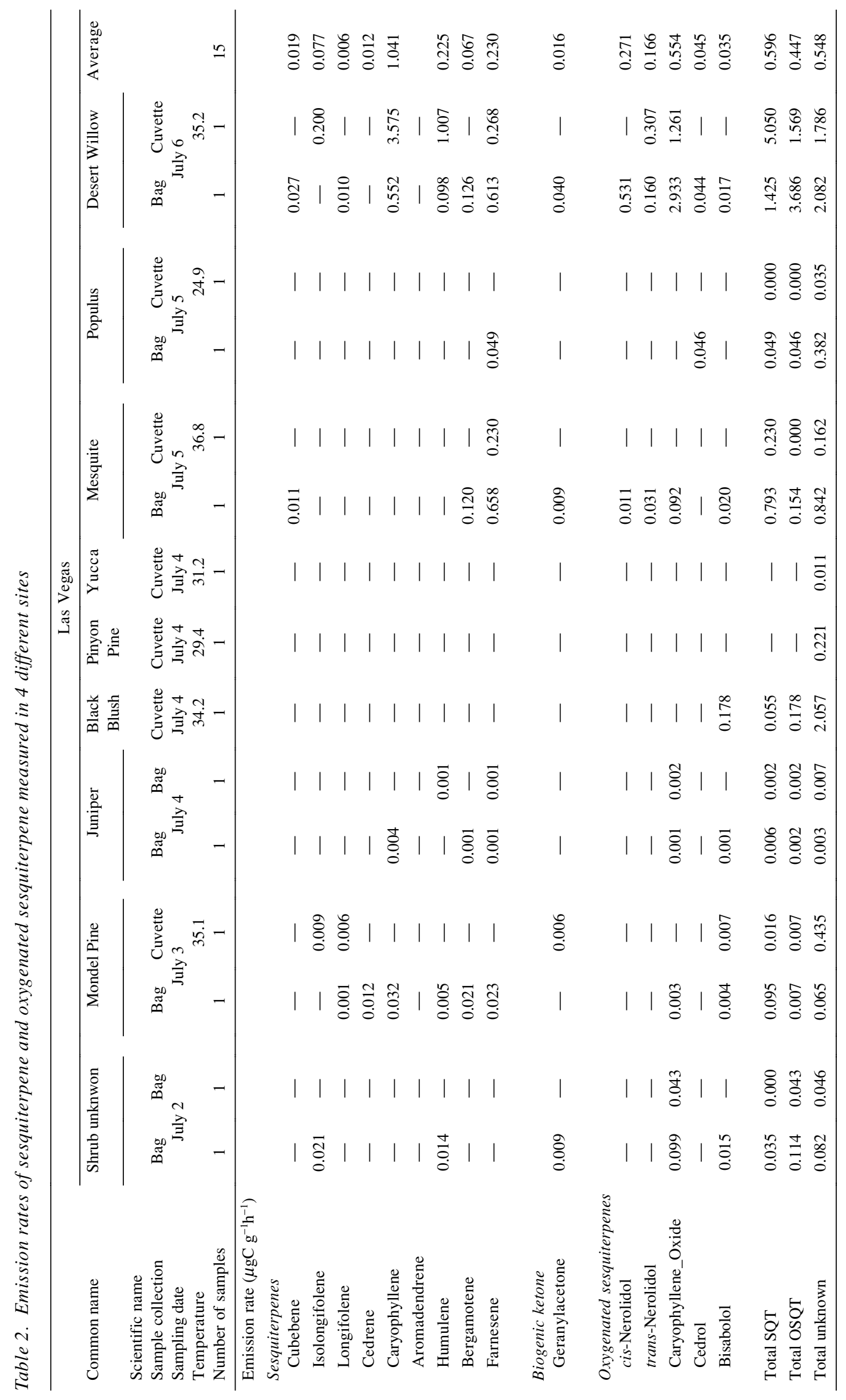




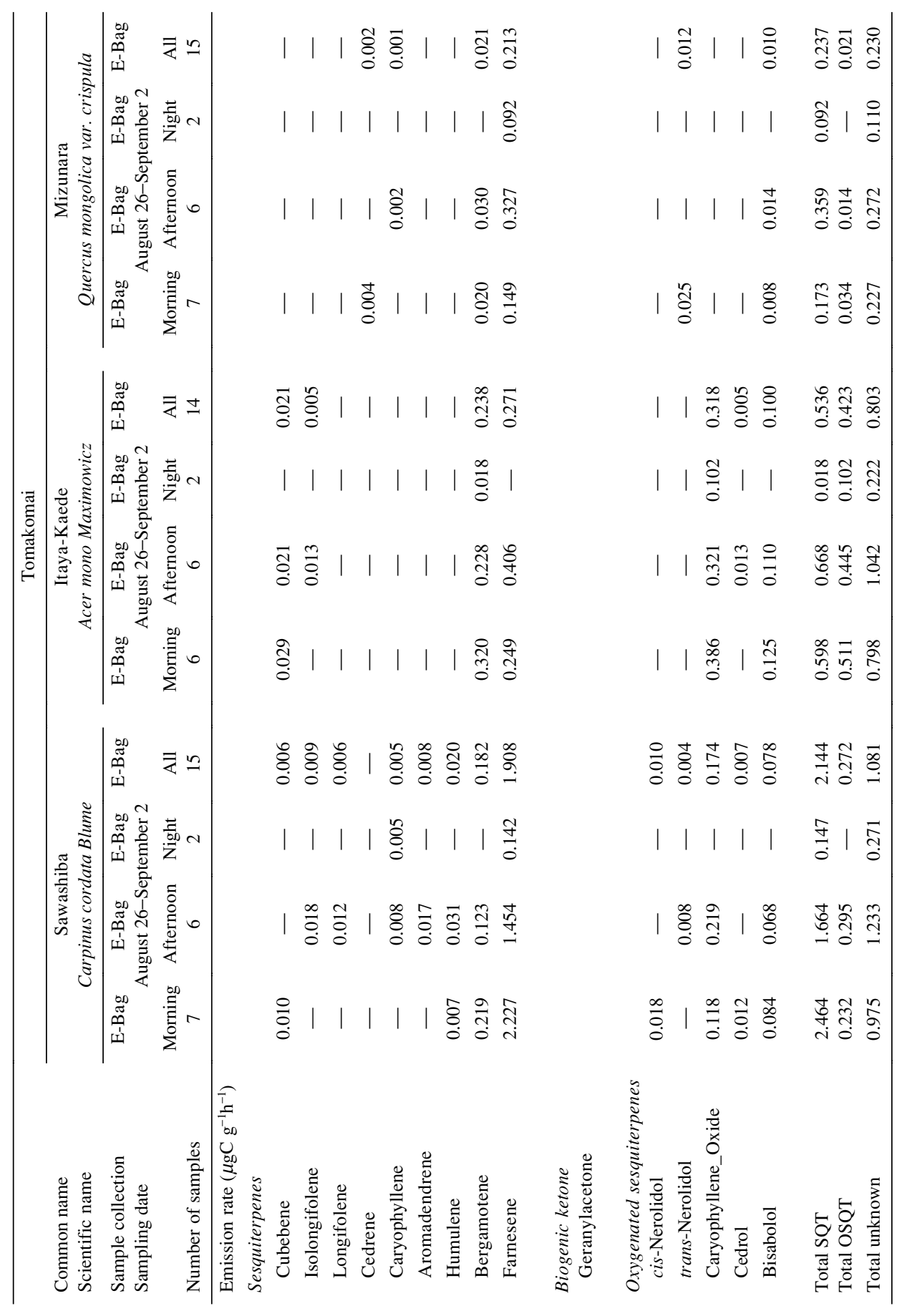




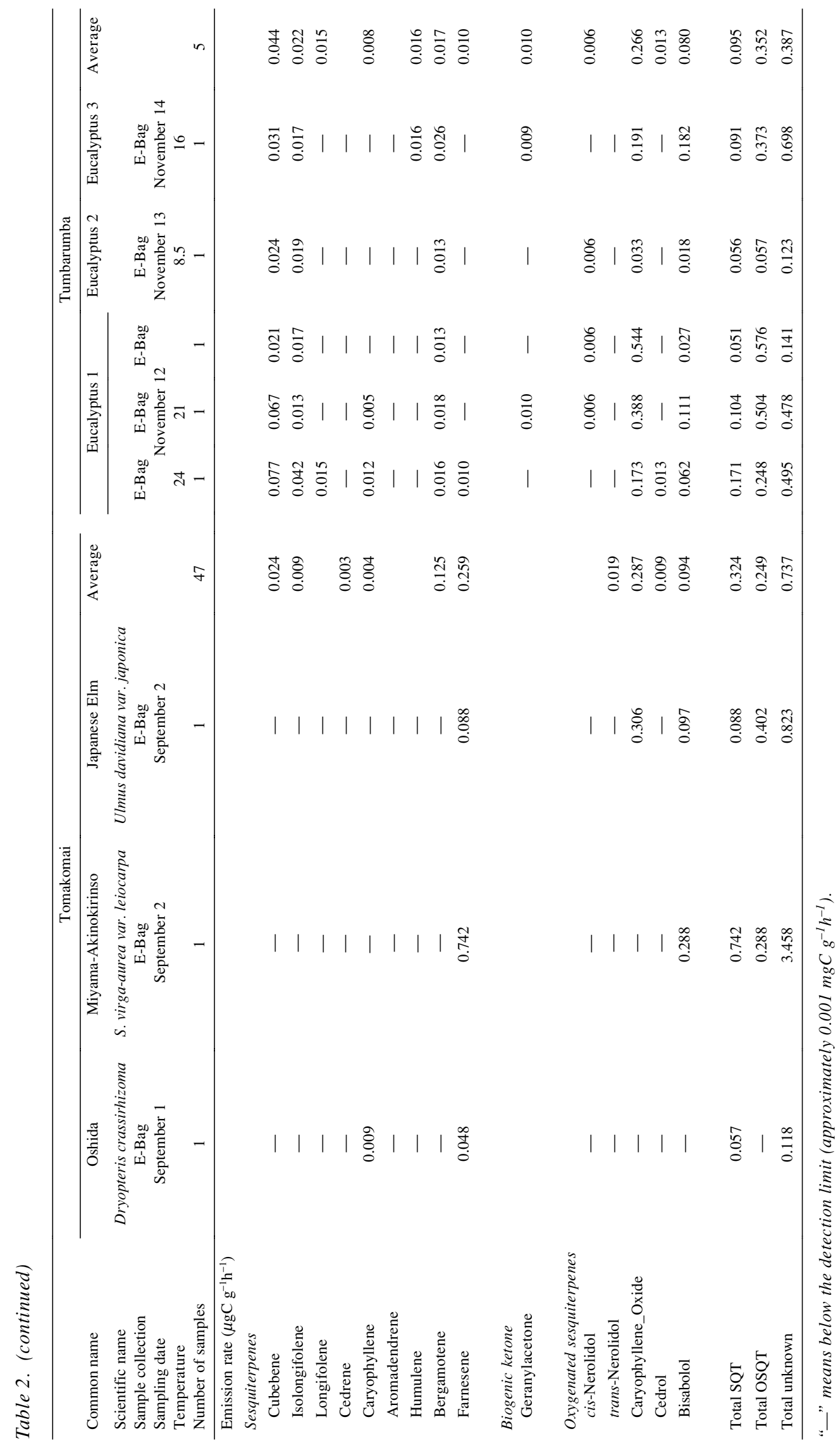




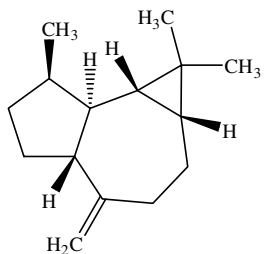

Aromadendrene

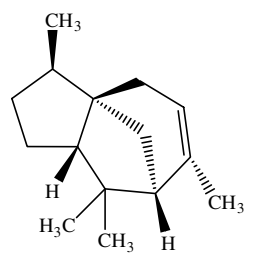

Cedrene

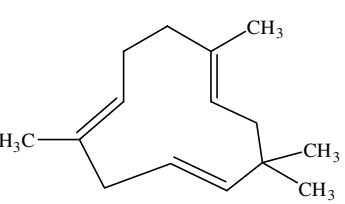

$\alpha$-Humulene

(Attracting parasite waspa ${ }^{\mathrm{a}}$

anti micro bial ${ }^{\mathrm{b}}$, anti-oxidant ${ }^{\mathrm{c}, \mathrm{d}}$

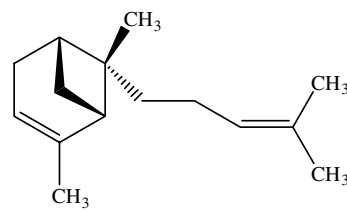

Bergamotene

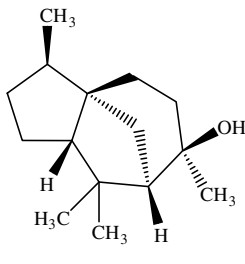

Cedrol

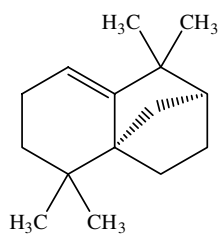

Isolongifolene<smiles>CC(C)=CCCC(C)(O)C1CC=C(C)CC1</smiles>

$\alpha$-Bisabolol (Wound healing $\mathrm{f}$, anti-mutagenic ${ }^{g}$ )

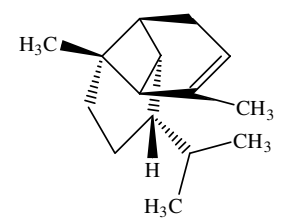

Copaene

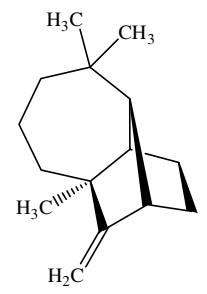

Longifolene

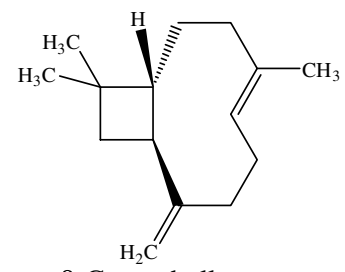

$\beta$-Caryophyllene

(Attracting parasite waspa

anti micro bial ${ }^{b}$, anti-oxidant ${ }^{\mathrm{c}, \mathrm{d}}$ )

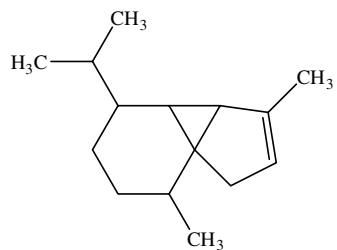

$\alpha$-Cubebene

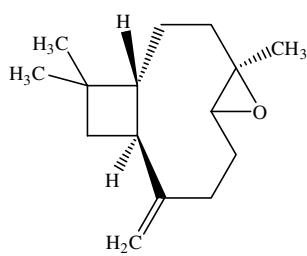

Caryophyllene oxide (Oxidation product of $\beta$-caryophyllene ${ }^{e}$ )

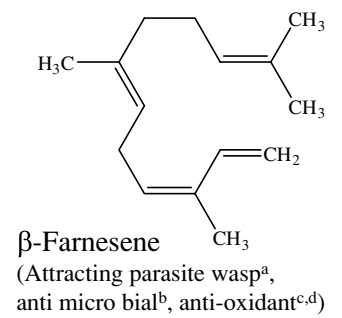

cis- and trans-Nerolidol

Fig. 2. Chemical structures with their known properties of sesquiterpenes (SQTs) and oxygenated SQTS (OSQTS) measured in this study (a: Turlings et al., 1990, b: Sonboli et al., 2006, c: Sonboli et al., 2005, d: McKay and Blumberg, 2006, e: Sköld et al., 2006, $f$ : Villegas et al., 2001, g: Gomes-Carneiro et al., 2005).

Inc., Gainesville, FL, U.S.A.). In most cases, collected compounds were extracted from the adsorbent immediately after sampling with approximately $2 \mathrm{ml}$ of dichloromethane. An exception was the Tumbarumba, Australia, samples which were transported to Boulder CO prior to sample extraction. Tests demonstrated that samples could be transported and stored prior to extraction without sample loss. After extraction from the collection trap, the samples were placed into $2 \mathrm{ml}$ glass vials, sealed with a plastic cap with PTFE liner and stored in a freezer (approximately $-15^{\circ} \mathrm{C}$ ) prior to being shipped back to the NCAR laboratory for analysis. Although they were covered with coolants, the samples from Las Vegas and Tomakomai were exposed to above-freezing temperatures $\left(0-10^{\circ} \mathrm{C}\right)$ during shipping. The extracts were concentrated by evaporating the solvent with a gentle argon flow in an NCAR laboratory (Boulder, CO, U.S.A.) to less than approximately $1-2 \mu \mathrm{l}$, and then $30 \mu \mathrm{l}$ of hexane was added to the vial to adjust the volume. These final solutions were stored in the freezer until analysis.

\section{Analysis}

A gas chromatograph (GC, HP5890GC, Agilent Technologies, U.S.A.) with a flame ionization detector (FID) was used for separation, quantification and identification of the compounds. The GC is equipped with a cold oncolumn injector and fused silica capillary column (HP-5, $0.32 \mathrm{~mm}$ i.d., $0.5 \mu \mathrm{m}$ film thickness, $60 \mathrm{~m}$ ) and uses helium as carrier gas. A $2 \mu \mathrm{l}$ aliquot of the final solution of the sample was injected into the GC. Compounds were identified by comparison of retention time with authentic standards and were quantified by comparison of peak area with a standard solution of the authentic standards which were gravimetrically quantified. Calibrations using a standard solution were performed every day and used to determine the amount of the compounds in samples injected within the same day. To determine the structure of some compounds, a GC/mass spectrometer (Varian GC/MS Saturn 2000, Varian Associates, Surrey, U.K.) was used to obtain a mass spectrum. Control (blank) samples were also collected directly from zero air flow. Identification and quantification of thirteen compounds in the 


\section{Las Vegas}
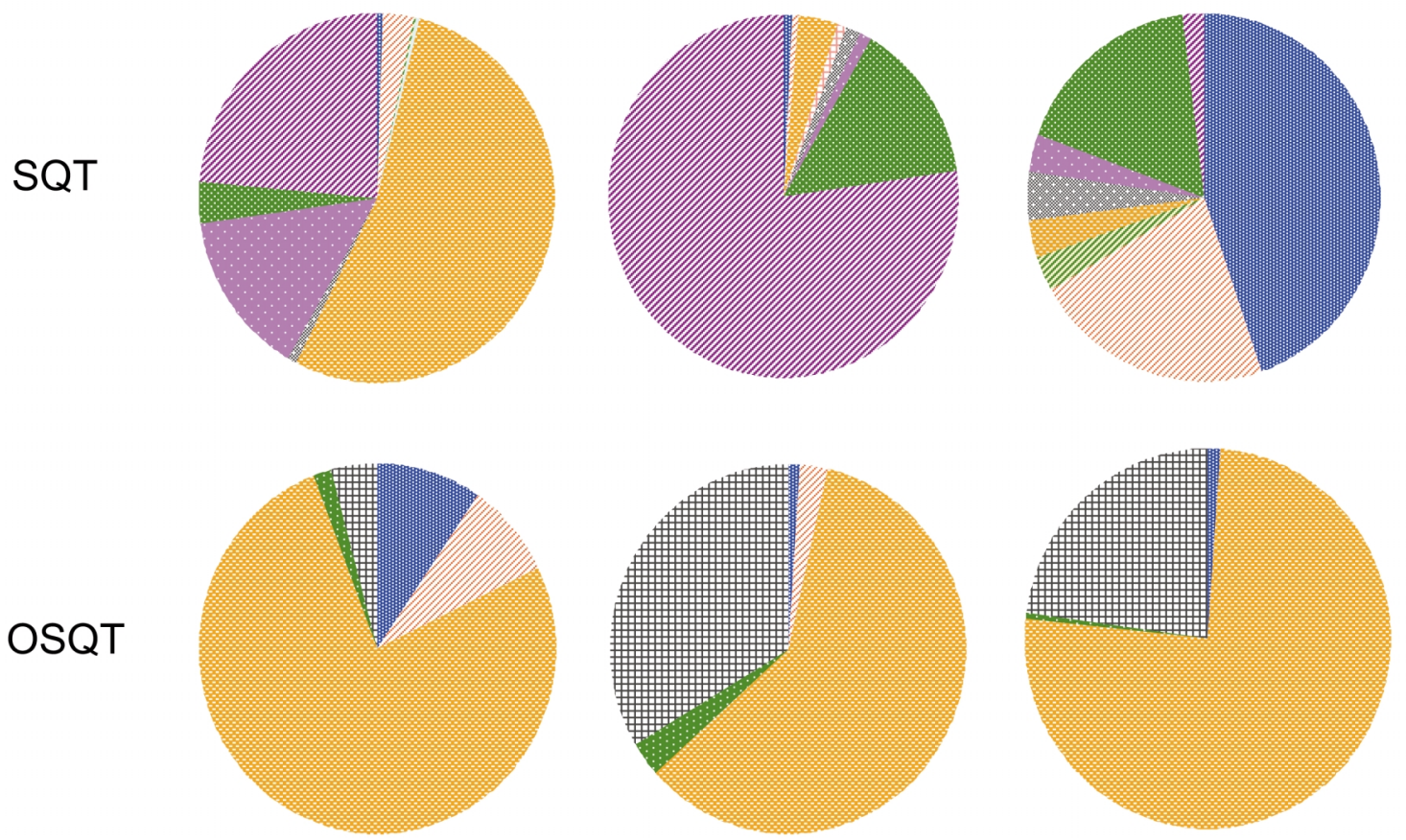

略 Cubebene

\& Isolongifolene

* Longifolene

: Caryophyllene

Geranylacetone

Humulene

Bergamotene

\# Farnesene

\section{OSQT}

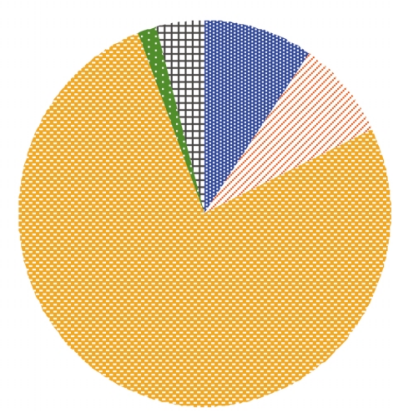

Fig. 3. Chemical distributions of SQT and OSQT collected in 3 field sites.

identified 15 SQT and OSQT are determined using authentic standards. Structure of Bergamotene and Farnesene were assumed from mass spectrum and their molecular ions. These compounds were quantified by a comparison of FID response with that of Humulene which is an isomer of these compounds. Obtained peak areas were corrected based on the "loss factor" which characterizes the fraction of the SQT or OSQT that remains in the final vial after the concentration process. The loss factor varied from 0.33 to 0.40 (average: 0.36 ) for the 13 compounds in the SQT-OSQT standard. The loss factor was obtained by a comparison of peak area of compounds in Ar concentrated solution and in a solution with a gravimetrically determined concentration. The emission rates of SQT and OSQT discussed in this report are adjusted using the loss factor. Expected uncertainty for emission measurement through whole analytical procedure was estimated to be around 10-15\%. We sampled the SQT and OSQT under a temperature controlled system only in Las Vegas. Temperatures shown in Table 2 except for Las Vegas sample are averaged temperature of 1-2 points of records within the sampling (2-4 hours). Therefore, the emission rates obtained without temperature control probably have larger uncertainties than those with the temperature control.

\section{RESUlTS AND DISCUSSION}

SQT emissions from temperate desert and forest plants

Eight SQTs and five oxygenated SQTs (OSQTs) were detected from samples collected in Las Vegas. Figure 2 shows the chemical structures of the compounds emitted from Las Vegas vegetation. Total emission rates of SQT and OSQT ranged from detection limit (approximately $0.001 \mu \mathrm{gC} \mathrm{g}^{-1} \mathrm{~h}^{-1}$ ) to 5.1 (average: 0.51$) \mu \mathrm{gC} \mathrm{g}^{-1} \mathrm{~h}^{-1}$ and to 3.7 (average: 0.39 ) $\mu \mathrm{gC} \mathrm{g}^{-1} \mathrm{~h}^{-1}$, respectively. These values are within the range of monoterpene emission rates observed for desert vegetation (Geron et al., 2006). Table 2 shows detected compounds and emission rates from sampled plants.

The enclosure bag lacked temperature control and leaf temperatures $\left(35-45^{\circ} \mathrm{C}\right)$ were higher than in the glass cuvette in which leaf temperature was regulated at around $30^{\circ} \mathrm{C}$, resulting in higher emission rates. This is in agreement with Helmig et al. (2004) observations that temperature is one of the important factors controlling the emission of detected SQT and other compounds. Major SQTs were $\beta$-Caryophyllene, $\alpha$-Humulene and $\beta$ Farnesene, which are known to attract parasitic wasps (Turlings et al., 1990) and to have an antimicrobial (Sonboli et al., 2006) and antioxidant activity (Sonboli 
et al., 2005; McKay and Blumberg, 2006). The major OSQT was Caryophyllene oxide which is an oxidation product of $\beta$-Caryophyllene (Sköld et al., 2006). It is most likely that plants generate these compounds to protect themselves and that emission of these compounds was enhanced by high temperature. Considering that the emission rates of the SQTs were comparable to those of monoterpenes (Janson and de Serves, 2001), SQTs can also be an important constituent of reactive BVOC. However, as mentioned above, the factors controlling SQT emission are probably much more complicated than that of isoprene emission, which can often be predicted as a function of climate condition and plant species composition. This is because SQTs are used for protection of plants from environmental interferences such as herbivore attack, microbial activity, oxidants and other stresses.

Nine SQTs and five OSQTs were detected from six temperate forest tree species. Total emission rates of SQT and OSQT ranged from 0.018 to 7.6 (average: 0.87$) \mu \mathrm{gC}$ $\mathrm{g}^{-1} \mathrm{~h}^{-1}$ and from 0.015 to 1.8 (average: 0.28$) \mu \mathrm{gC} \mathrm{g}^{-1} \mathrm{~h}^{-1}$, respectively. The average emission level was similar to that of Las Vegas experiment (see Table 2) and are within the range of monoterpene emissions observed for temperate forests (Guenther et al., 2006). However, the chemical speciation was not similar and the major SQT, bergamotene, was different than what was observed from Las Vegas vegetation. Caryophyllene, the dominant SQT observed in Las Vegas, was a minor component of the Tomakomai samples. Figure 3 compares the chemical distribution of emissions of the four major SQTs measured in the three field sites. The distribution of SQT and OSQT are quite different in sampling location and plant species. The differences in SQT chemical speciation at the sites could be caused by genetic and/or environmental differences (e.g., climate, soil characteristics, herbivory, herbivore predation, etc.; Ortega and Helmig, 2008). Bergamotene has similar functions (anti-microbial, predator attractive, etc.) as other major SQTs such as $\beta$ Caryophyllene, $\alpha$-Humulene and $\beta$-Farnesene. Major OSQTs were Caryophyllene oxide and $\alpha$-Bisabolol. $\alpha$ Bisabolol is an alcoholic SQT which has wound healing (Villegas et al., 2001) and antimutagenic (GomesCarneiro et al., 2005) activities. Figures $4 \mathrm{a}-\mathrm{c}$ presents temporal variation of total SQT and OSQT emission from Carpinus cordata Blume, Acer mono Maximowicz and Quercus mongolica var. crispula from August 25 to September 2, 2006. Total SQT and OSQT emission rates were correlated with ambient temperature and light intensity.

Both SQT and OSQT were detected in emissions from these three species. However, emission rates and the ratio between SQT and OSQT varied between species. The ratio between SQT and OSQT also varied with time for individual plants (see Figs. 4a and b). In Figs. 4a and b, SQT accounted for larger part in total emission until Au-

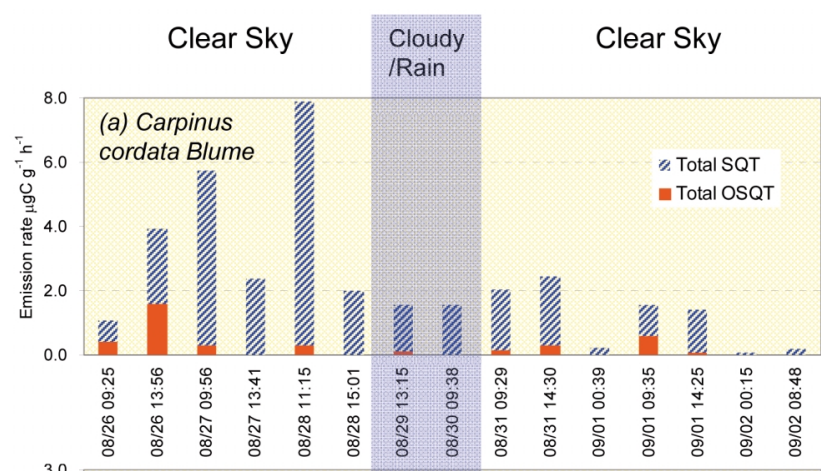

(b) Acer mono Maximowicz
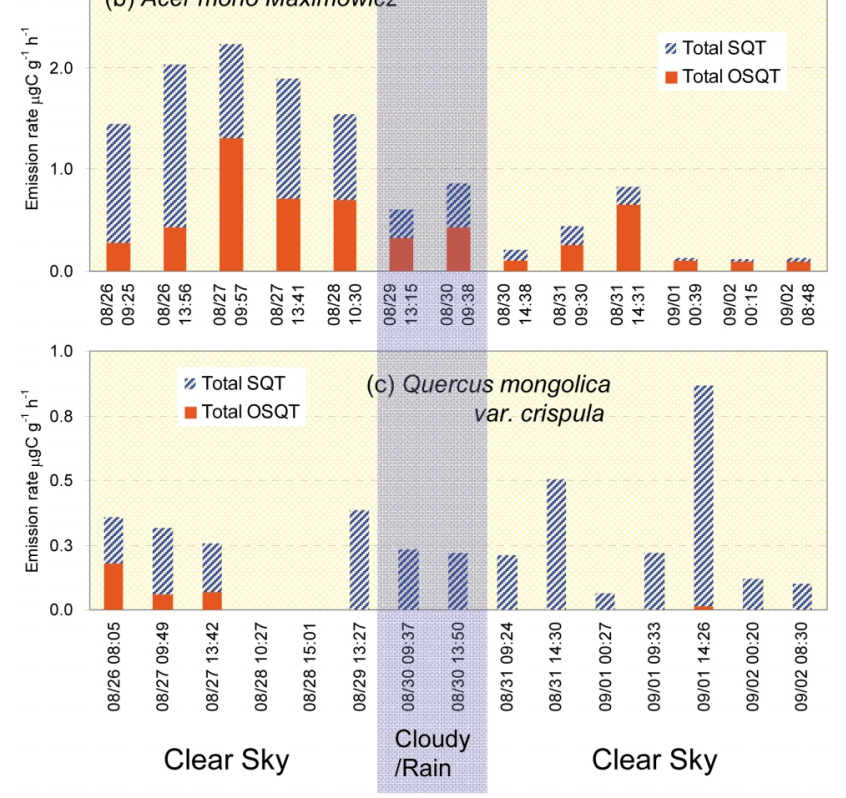

Fig. 4. Temporal variations of averaged $S Q T$ and $O S Q T$ emission from 3 major species in the experimental forest in Tomakomai.

gust 28. As seen in the figure, clear skies occurred until the 28th followed by light rains on the 29th and 30th with cloudy and humid conditions. Although no evidence has been found, this could be explained by a hypothesis that enhanced SQT emissions during drier conditions may improve a plant's ability to induce predators with the emitted SQTs since predators are more likely to be active during dry conditions. However, Quercus mongolica var. crispula did not show this trend. Further investigations are required to determine the importance of this potential atmosphere-ecosystem interaction.

Major SQTs from Eucalyptus were Cubebene, Isolongifolene and Longifolene. None of the four major SQTs in Las Vegas and Tomakomai plant emissions were observed at substantial emission rates from these Eucalyptus. Caryophyllene oxide and $\alpha$-Bisabolol were detected as the major OSQTs. Total emission rate of SQT 
ranged from 0.051 to $0.17 \mu \mathrm{gC} \mathrm{g}^{-1} \mathrm{~h}^{-1}$ (average: 0.095 ). Total OSQT ranged from 0.057 to $0.58 \mu \mathrm{gC} \mathrm{g}^{-1} \mathrm{~h}^{-1}$ (average: 0.36 , see Table 2). On the other hand, a relatively high emission of an unknown compound was also detected. The compound was not detected at the other sites and seems to have similar molecular weight and polarity to SQTs. The emission rate was estimated to be 5-10 times higher than that of other detected SQTs at this site. The GC/MS analysis could not determine either its molecular weight or structure.

The variability in observed SQT and OSQT emission rates is relatively high compared to other BVOC including isoprene and monoterpenes. This may be due both to genetic variability and because SQT and OSQT seem to be more sensitive to highly variable biological and physical conditions, including herbivore and other forms of stress. This high degree of variability complicates efforts to accurately parameterize models of SQT and OSQT emissions.

Relative contribution of SQTS and OSQTs to ecosystem scale BVOC emissions.

The BVOCs discussed in this paper such as SQT and OSQT are likely to contribute on formation of biogenic aerosol as either constituents or precursors. Because even $\mathrm{C}_{16}$ normal alkane is detected as an aerosol component (Eichmann et al., 1979; Fraser et al., 2002), OSQTs, which have larger molecular weight and are more polar, are likely to be contained in aerosols as constituents. In addition, oxidation products of monoterpene are known to form organic aerosol in the forest (Kavouras et al., 1998, 1999). Pandis et al. (1991) reported that $0.1-8 \%$ of monoterpene ( $\beta$-pinene) can be converted into aerosols via its oxidation process. Because SQT and OSQT have 15 carbon atoms in their molecule, they are also likely to contribute aerosols efficiently as components and also as precursors (Griffin et al., 1999).

Emission factors estimated from measurements in the Tomakomai Experimental Forest were used to parameterize the Model of Emissions of Gases and Aerosols from Nature, (MEGAN version 2.0, Guenther et al., 2006) and used to estimate landscape average emission rates of SQT and OSQT. The daytime emission of SQT and OSQT were estimated to be 72-710 (average: 460) $\mu \mathrm{gC} \mathrm{m}{ }^{-2} \mathrm{~h}^{-1}$ and 38-370 (average: 240$) \mu \mathrm{gC} \mathrm{m}^{-2} \mathrm{~h}^{-1}$, respectively. Those values exceed monoterpene emission observed in a boreal forest (Janson et al., 1999). Considering that several of the SQT and OSQT probably form organic aerosol via oxidation, this is a significant source of biogenic aerosol. About $70 \%$ of the emitted $\beta$ caryophyllene reacts within the canopy with the remainder escaping to the atmospheric boundary layer (Stroud et al., 2005; Shu and Atkinson, 1995) where it will also be oxidized and form aerosol. This strongly suggests that
SQT and OSQT are important not only as reactive hydrocarbons but also as aerosol components and precursors.

\section{CONCLUSION}

Terrestrial vegetation can emit SQT and OSQT to the atmosphere at rates similar to monoterpene emissions, which are broadly known as an important reactive BVOC, although the annual global total emission of SQT and OSQT may be an order of magnitude lower than monoterpene emissions. Average OSQT emissions, which are quite few reported, range from being a factor of 3 lower than SQT to a factor of 3 higher and appear to be an important component of total BVOC emission SQT and OSQT emissions from a cool temperate forest were possible to be correlated with ambient humidity and soil moisture. The ratio between SQT and OSQT also varied and may be related to differences in their function. Further research will be needed to understand the factors controlling SQT and OSQT emissions. Finally, SQT and OSQT are suggested to have an important role as aerosol component and precursors because those have much lower vapor pressure than monoterpenes and SQT. This means that OSQT has higher efficiency to generate organic aerosols as a precursor and that the OSQT also has a possibility to contribute as a component of the aerosol by itself. In addition, the investigation of high molecular weight BVOCs is essential for understanding the role of aerosol in biosphere atmosphere interactions.

Acknowledgments - This study is partly funded by the Japan Society for the Promotion of Science (Grant-in-Aid for scientific research 18254001), Desert Research Institute (DRI) and the Advanced Study Program in National Center for Atmospheric Research (NCAR). We thank Mr. Atsushi Okuda at Tomakomai Experimental Forest and students in Prof. Kajii's group at Tokyo Metropolitan University for supporting the field experiment in Tomakomai. We also thank Dr. Arata Yajima at Tokyo University of Agriculture for providing standard for diterpene. The NCAR is sponsored by the U.S. National Science Foundation.

\section{REFERENCES}

Calogirou, A., Kotzias, D. and Kettrup, A. (1997) Product analysis of the gas-phase reaction of $\beta$-caryophyllene with ozone. Atmos. Environ. 31(2), 283-285.

Eichmann, R., Neuling, P., Ketseridis, G., Hahn, J., Jaenicke, R. and Junge, C. (1979) n-Alkanes studies in troposphereI. Gas and particulate concentrations in north Atlantic air. Atmos. Environ. (1967) 13(5), 587-599.

Fraser, M. P., Yue, Z. W., Tropp, R. J., Kohl, S. D. and Chow, J. C. (2002) Molecular composition of organic fine particulate matter in Houston, TX. Atmos. Environ. 36, 5751-5758.

Geron, C., Guenther, A., Greenberg, J., Karl, T. and Rasmussen, R. (2006) Biogenic volatile organic compound emissions 
from desert vegetation of the southwestern US. Atmos. Environ. 40, 1645-1660.

Gomes-Carneiro, M. R., Dias, D. M. M., De-Oliveira, A. C. A. X. and Paumgartten, F. J. R. (2005) Evaluation of mutagenic and antimutagenic activities of $\alpha$-bisabolol in the Salmonella/microsome assay. Mutation Res. 585, 105-112.

Griffin, R. J., Cocker, D. R., III, Seinfeld, J. H. and Dabdub, D. (1999) Estimate of global atmospheric organic aerosol from oxidation of biogenic hydrocarbon. Geophys. Res. Lett. 26(17), 2721-2724.

Guenther, A., Karl, T., Harley, P., Wiedinmyer, C., Palmer, P. I. and Geron, C. (2006) Estimates of global terrestrial isoprene emissions using MEGAN (Model of Emissions of Gases from Nature). Atmos. Chem. Phys. 6, 3181-3210.

Helmig, D., Revermann, T., Pollmann, J., Kaltschmidt, O., Jimenez Hernadez, A., Bocquet, F. and David, D. (2003) Calibration system and analytical consideration for sesquiterpene determination in air. J. Chromatogr. A $\mathbf{1 0 0 2}$, 193-211.

Helmig, D., Bocquet, F., Pollmann, J. and Revermann, T. (2004) Analytical techniques for sesquiterpene emission rate studies in vegetation enclosure experiments. Atmos. Environ. 38, 557-572.

Himejima, M., Hobson, K. R., Otsuka, T., Wood, D. L. and Kubo, I. (1992) Antimicrobial terpenes from oleoresin of Ponderosa Pine tree Pinus ponderosa: A defense mechanism against microbial invasion. J. Chem. Ecol. 18(10), 18091818.

Hiura, T. (2001) Stochasticity of species assemblage of canopy trees and understory plants in a temperate secondary forest created by major disturbances. Ecol. Res. 16, 887-893.

Hiura, T. (2005) Aboveground biomass and net biomass increment in a cool temperate forest on a landscape scale. Ecol. Res. 20, 271-277.

Hoffmann, T., Odum, J. R., Bowman, F., Collins, D., Klockow, D., Flagan, R. C. and Seinfeld, J. H. (1997) Formation of organic aerosol from the oxidation of biogenic hydrocarbons. J. Atmos. Chem. 26, 189-222.

Janson, R. and de Serves, C. (2001) Acetone and monoterpene emissions from the boreal forest in northern Europe. Atmos. Environ. 35, 4629-4637.

Janson, R., de Serves, C. and Romero, R. (1999) Emission of isoprene and carbonyl compounds from a boreal forest and wetland in Sweden. Agri. Forest Meteorol. 98-99, 671-681.

Kavouras, I. G., Mihalopoulos, N. and Stephanou, E. G. (1998) Formation of atmospheric particles from organic acids produced by forests. Nature 395, 683-686.

Kavouras, I. G., Mihalopoulos, N. and Stephanou, E. G. (1999) Secondary organic aerosol formation vs primary organic aerosol emission: in situ evidence for the chemical coupling between monoterpene acidic photooxidation products and new particle formation over forests. Environ. Sci. Technol. 33, 1028-1037.

McKay, D. L. and Blumberg, J. B. (2006) A review of the bioactivity and potential health benefits of Chamomile Tea
(Matricaria recutita L.). Phytother. Res. 20, 519-530.

Ortega, J. and Helmig, D. (2008) Approaches for quantifying reactive and low-volatility biogenic organic compound emissions by vegetation enclosure techniques-Part A. Chemosphere 72, 343-364.

Pandis, S. N., Paulson, S. E., Seinfeld, J. H. and Flagan, R. C. (1991) Aerosol formation in the photooxidation of isoprene and $\alpha$-pinene. Atmos. Environ. 25A(5/6), 997-1008.

Shibata, H., Hiura, T., Tanaka, Y., Koike, T. and Takagi, K. (2005) Carbon cycling and budget at a forested basin in southwestern Hokkaido, northern Japan. Ecol. Res. 20, 325331.

Shu, Y. and Atkinson, R. (1995) Atmospheric lifetimes and fates of a series of sesquiterpenes. J. Geophys. Res. 100(D4), 7275-7281.

Sköld, M., Karlberg, A.-T., Matura, M. and Börje, A. (2006) The fragrance chemical $\beta$-caryophyllene-air oxidation and skin sensitization. Food Chem. Toxicol. 44, 538-545.

Smith, R. H. (1963) Toxicity of pine resin vapors to three species of Dendroctonus bark beetles. J. Econom. Entomol. 56(6), 827-831.

Sonboli, A., Salehi, P., Reza Kanani, M. and Nejad Ebrahimi, S. (2005) Antimicrobial and antioxidant activity and essential oil composition of Grammosciadium scabridum Boiss. from Iran. Z. Naturforsch. 60c, 534-538.

Sonboli, A., Babakhani, B. and Reza Mehrabian, A. (2006) Antimicrobial activity of six constituents of essential oil from Salvia. Z. Naturforsch. 61c, 160-164.

Stroud, C., Makar, P., Karl, T., Guenther, A., Geron, C., Turnipseed, A., Nemitz, E., Baker, B., Potosnak, M. and Fuentes, J. D. (2005) Role of canopy-scale photochemistry in modifying biogenic-atmosphere exchange of reactive terpene species: Results from CELTIC field study. J. Geophys. Res. 110, D17303, doi:10.1029/2005JD005775.

Suni, T., Kulmala, M., Hirsikko, A., Bergman, T., Laakso, L., Aalto, P., Leuning, R., Cleugh, H., Zegelin, S., Hughes, D., van Gorsel, E., Kitchen, M., Vana, M., Horrak, U., Mirme, S., Mirme, A., Twining, J. and Tadros, C. (2007) Formation and characteristics of ions and charged aerosol particles in a native Australian Eucalypt forest. Atmos. Chem. Phys. Discuss. 7, 10343-10369.

Turlings, T. C. J., Tumlinson, J. H. and Lewis, W. J. (1990) Exploitation of herbivore-induced plant odors by host-seeking parasitic wasps. Science 250(4985), 1251-1253.

Villegas, L. F., Marcalo, A., Martin, J., Fernandez, I. D., Maldonado, H., Vaisberg, A. J. and Hammond, G. B. (2001) (+)-epi- $\alpha$-bisabolol is the wound-healing principle of Peperomia galioides: Investigation of the in vivo wound healing activity of related terpenoides. J. Nat. Prod. 64, 1357-1359.

Werner, R. A. (1995) Toxicity and repellency of 4-allyanisole and monoterpenes from White Spruce and Tamarack to the Spruce Beetle and Eastern Larch Beetle (Coleoptera: Scolytidae). Physiological Chem. Ecol. 24(2), 372-379. 